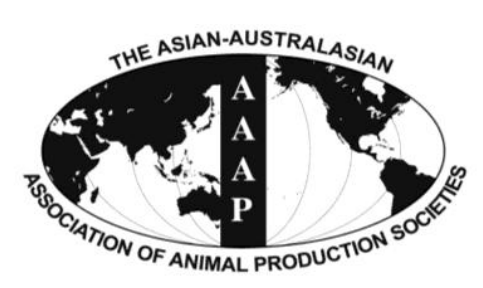

\title{
Comparison of Milk Yield and Animal Health in Turkish Farms with Differing Stall Types and Resting Surfaces
}

\author{
Nurcan Karslioglu Kara, Askin Galic ${ }^{1}{ }^{1 *}$, and Mehmet Koyuncu \\ Department of Animal Science, Faculty of Agriculture, Uludag University, Bursa 16059, Turkey
}

\begin{abstract}
The current study was carried out to determine the influence of different resting surfaces and stall types on milk yield and animal health. Study was carried out in Bursa that is one of the most important cities of Turkey in terms of dairy production. Effects of resting surfaces and stall types on milk yield were found to be important. Also influence of different resting surfaces and stall types on lactation length was examined and found that rubber mats were different from the two other options. Relationships between different resting surfaces or stall types and health problems were examined and connection between stall type and repeat breeding (RB), dystocia, retained placenta and a connection between resting surface types and RB and clinical mastitis were found to be important. Considering their economic reflections, it can be said that results are quite important to the Turkish dairy industry. (Key Words: Resting Surface, Stall Type, Milk Yield, Cattle, Health Problems)
\end{abstract}

\section{INTRODUCTION}

With many confounding factors present on commercial farms, it is questionable whether husbandry systems have the desired effect of improving animal health and welfare (Regula et al., 2004). Housing systems and resting surface types have an influence on milk yield and reproductive performance as much as feeding and keeping methods in dairy herds. This effect is indirect due to relationship between housing systems- resting surface and foot diseases (De Graves and Fetrow, 1993; Phillips and Morris, 2001; Kara et al., 2011) and is direct due to effect of housing systems-resting surface on mastitis and reproduction performance (Coleman et al., 1985; Valde et al., 1997). When summarizing the findings of other authors who compared the effect of tie-stall (TS) or free-stall (FS) housing on cows' milk performance, health, fertility and behavior, Zdziarski et al. (2002) concluded that none of the systems was clearly superior, although the FS system had

\footnotetext{
* Corresponding Author: Askin Galic. Tel: +90-242-3102497, Fax: +90-242-2274564, E-mail: galic@ akdeniz.edu.tr

${ }^{1}$ Department of Animal Science, Faculty of Agriculture, Akdeniz University, Antalya 07058, Turkey.

Submitted May 16, 2014; Revised Jul. 8, 2014; Accepted Aug. 4, 2014
}

some advantages.

Milk yield is affected by many factors and one of these is husbandry. Stall and resting surface types as elements of the environment are important for dairy herds because of effects on not only milk yield but also health problems related to reproduction and milk yield. Therefore, the aim of the study was to investigate the influence of different resting surfaces and stall types on milk yield and some production diseases. Study was carried out in Bursa, located in north-western part of Turkey. Because Bursa has a great potential for dairy production of Marmara region that is the keystone of the Turkish dairy industry. Therefore, the results obtained in this area can be used for regional assessment. Furthermore, although there is considerable research regarding similar topics (Regula et al., 2004; Calamari et al., 2009; Sawa and Bogucki, 2011), it has not been previously investigated in this region.

\section{MATERIAL AND METHODS}

\section{Selection of cows}

In this study 709 lactating cows within normal managerial limits (lactation length: $\min 260 \mathrm{~d}$; $\max 400 \mathrm{~d}$ ) were examined in 37 dairy herds. For each cow, the 
following data was collected: lactation length (day), milk yield $(\mathrm{kg})$, and the presence of some health problems (dystocia, retained placenta [RP], clinical mastitis [CM], repeat breeding $[\mathrm{RB}]$ as "yes" or "no". Lactation length (day) and milk yield $(\mathrm{kg})$ data were collected at the end of lactation from the database of Cattle Breeders' Association of Bursa.

\section{Selection of herds}

A total of 37 herds which are members of Cattle Breeders' Association of Bursa were selected in the same or similar geographic area of the city. Herds were visited during the summer season and 22 of 37 herds included in the study housed lactating cows in FS, while 15 herds housed in TS. All FS herds had outdoor areas for the cows to lie down on if desired. For each herd that was under identical management conditions the following data were collected: stall type (FS, TS), resting surfaces (concrete, sand and rubber). Influence of different stall type and resting surfaces on milk yield and some production diseases were investigated in 6 FS herds with sand, 3 FS herds with rubber, 13 FS herds with concrete and 15 TS herds with concrete resting surfaces.

\section{Statistical analyses}

Between the stall types, only FS herds with concrete resting surface were compared with TS with concrete resting surfaces because there was no other resting surface option for TS herds. Due to similar reason, influence of concrete, sand or rubber resting surface on milk yield was compared only in the FS herds. Mean milk yield of cows from the same herd was calculated to determine the effect of herd type on the character, $t$ test was used to compare the means of FS or TS herds with concrete resting surface. Also, one-way analysis of variance was used to compare the means of FS herds with concrete, sand or rubber resting surface to determine whether milk yield is affected by resting surface. In order to test the association between resting surfaces or stall types and some production diseases, Chi-squared $\left(x^{2}\right)$ test was used. Data were analyzed using SPSS 17.0.

\section{RESULTS AND DISCUSSION}

\section{Comparison of milk yield and lactation length in}

\section{different stall types}

World wide, cows are generally housed in either TS or FS barns. While each cow has a separate stall that permits individual attention during feeding, grooming and milking in TS, in FS cows have a resting area that is divided into individual stalls without ties and can move freely. The TS are the most common for small herd size (20 or less head) and each has advantages and limitations, which may differentially affect milk quantity and quality (Skrzypek, 2002). In recent years, FS barns have become more desirable than TS barns (even in developing countries with mostly small size herds) because of lower disease incidence and fertility problems and higher milk yields (Valde et al., 1997).

Milk yield was compared between TS and FS that used concrete resting surface because there was no other options of resting surfaces for TS barns in this study. The effects of stall type on milk yield and lactation length are shown in Table 1. The averages for milk yield and lactation length of 467 cows were $6,120.1 \mathrm{~kg}$ and 333.2 days, respectively. According to the results, there was a significant difference in milk yield between the two stall types. The average for milk was $321 \mathrm{~kg}$ higher for housed cows in FS than for those housed in TS $(\mathrm{p}<0.01)$.

As is seen in Table 1, there was a significant difference in milk yield between two different stall types with same resting surface. One of the underlying reasons for this result could be that all cows housed in FS barns preferred outdoors for resting and the outdoor surface of all FS barns in this study was pressed soil which is softer than concrete. Preference studies show that given a choice, cows preferred and spent more time lying on softer bedding like rubber or sand and increasing lying time has positive effect on udder health and milk production (Tucker and Weary, 2001). Also, there is some evidence that FS housing and regular outdoor exercise have positive effects on health, welfare and production of dairy cows (Regula et al., 2004). The second reason could be the management practices of the owners as TS barns are often used by small-scale producers that have a lesser ability for investment and technology adoption (Kumlu, 2008). The third reason could be due to the limited number of animals used in the study. As to lactation length, there is no significant difference between two different stall types with same resting surface in this study.

Table 1. Means $( \pm$ SE) of milk yield and lactation length in two different stall types

\begin{tabular}{lcccccc}
\hline \multirow{2}{*}{ Stall type } & \multirow{2}{*}{ Cow } & \multicolumn{2}{c}{ Milk yield $(\mathrm{kg})$} & & \multicolumn{2}{c}{ Lactation length $(\mathrm{d})$} \\
\cline { 3 - 4 } \cline { 6 - 7 } & & Mean \pm SE & $\mathrm{p}$ & & Mean \pm SE & $\mathrm{p}$ \\
\hline Tie-stall & 232 & $5,958.5 \pm 73.47$ & 0.002 & & $336.5 \pm 2.42$ & 0.899 \\
Free-stall & 235 & $6,279.7 \pm 59.12$ & & & $330.0 \pm 2.42$ & \\
Average & & $6,120.1 \pm 47.62$ & & $333.2 \pm 1.72$ & \\
\hline
\end{tabular}

SE, standard error. 
Comparison of milk yield and lactation length in different resting surface

Some housing types especially those with poor and unhygienic bases or resting surface types, often give rise to udder problems and risk of mastitis which directly effects milk yield (Cook, 2002). Many factors are involved in selection of suitable resting surface types including cost, availability, and cow comfort, ease of use, waste storage and disposal methods available to the farm. Ideal bedding should be dry, inert (to microbial growth), cost effective, contribute to cow comfort and cleanliness and easily managed (Tucker et al., 2003).

The effects of resting surface types on milk yield and lactation length are shown in Table 2. There was a significant difference between mean milk yield and lactation length of herds used rubber resting surface and the others $(\mathrm{p}<0.01)$.

In this study, there were differences of over a tonne in milk yield and approximately 2 weeks in lactation length in between rubber resting surface and the others. The first reason for these results could be increased lying time because type of resting surface in the stall may affect the time spent lying down. Previous work has shown that cows tend to spend more time lying on softer surfaces (Tucker and Weary, 2001) and blood flow to the udder is increased during lying (Metcalf et al., 1992). Furthermore, when cows are deprived of lying time, growth hormone in plasma is reduced with negative effects on milk yield (Munksgaard and Løvendahl, 1993). The second reason could be that the necessary hygienic conditions for udder health are better provided with rubber bedding. Bedding may play a key role in the transfer of environmental pathogens to the udder. Because teats are in close contact with bedding and the bacteria it harbors for prolonged periods (Carroll, 1977) and rubber stay cleaner than concrete (Herlin, 1997). There was a reduction by almost $50 \%$ in the somatic cell count in herds with rubber mats compared with concrete (Østerås and Lund, 1988), and Valde et al. (1997) found the incidence rate of mastitis reduced by $14 \%$ in herds with rubber mats compared with concrete floors. The reason for the difference between two soft beddings (rubber and sand), could be due to the preference of cows. Although sand has

Table 2. Means $( \pm$ SE) of milk yield and lactation length on three different resting surfaces

\begin{tabular}{lllc}
\hline $\begin{array}{c}\text { Bedding } \\
\text { type }\end{array}$ & Cow & Milk yield (kg) & Lactation length (d) \\
\hline Concrete & 235 & $6,279.7 \pm 59.12^{\mathrm{a}}$ & $323.0 \pm 2.42^{\mathrm{a}}$ \\
Sand & 130 & $6,314.9 \pm 106.24^{\mathrm{a}}$ & $325.0 \pm 3.22^{\mathrm{a}}$ \\
Rubber & 112 & $7,402.7 \pm 133.43^{\mathrm{b}}$ & $341.9 \pm 2.90^{\mathrm{b}}$ \\
Average & & $6,553.0 \pm 55.87$ & $331.4 \pm 1.65$ \\
\hline
\end{tabular}

SE, standard error.

Means in a column with no common superscript differ significantly $(\mathrm{p}<0.01)$. increased in popularity as a bedding type, it is often not preferred by the cows (Norring et al., 2008). Manninen et al. (2002) found that cows avoided sand. According to results of this study, standing times could have been higher depending on preference of cows for rubber rather than sand surface, therefore, milk production was affected negatively and milk yield and lactation length were lower.

\section{Comparison of health problems related to milk yield and reproduction in different stall types and resting surface}

Reproduction is one of the key pillars of dairy production and reproductive performance is linked to periparturient health problems (LeBlanc, 2008). In these periods, most common health problems can be considered as dystocia, RP, RB, and mastitis. Previous work has shown that housing systems effects cow health and welfare (Tucker and Weary, 2001; Kara et al., 2011). There is some evidence that FS housing and regular outdoor exercise have positive effects on health and welfare of dairy cows (Regula et al., 2004). Valde et al. (1997) reported that herds with TS were found to have a higher $\mathrm{CM}$ rate and a lower mean fertility status index. Nogalski (2006) observed that FS housed cows had better fertility compared to TS housed cows. However, there is not enough research regarding the relationship between stall type and some health problems, especially dystocia or RP, which negatively affects reproduction.

Influence of resting surface and stall type on some health problems (CM, dystocia, RP, and $\mathrm{RB})$ in this study were analyzed with $x^{2}$ test and as it can be seen from the Table 3, the relationships between stall type and RB, dystocia, and RP were found to be significant $(\mathrm{p}<0.01)$.

According to results of our study, incidence of health problems encountered in calving and after calving were found lower in FS. One of the reasons could be free movement choice for animal in FS barns. Freedom of movement in the group pen allows animals to freely express their natural instincts and behaviors, which is of particular importance for the total reproductive period (from first insemination to calving) (Sawa and Bogucki, 2011). A second reason could be the average age of cows in TS herds, although it was not evaluated statistically, there was a tendency to keep animals longer in TS herds included in this study. Reproductive disorders and reproductive performance are associated with age and older cows to have a higher incidence of RP than cows delivering their second and third calves (Muller and Owens, 1974). The third reason could be poor management practice relevant to feeding. Feeding errors are known to be the main factor in metabolic diseases like RP and poorer reproductive parameters of the cows (Stevenson, 2001).

The RB and CM are the most frequent and economical 
Table 3. Associations between stall and resting surface types and some health problems

\begin{tabular}{|c|c|c|c|c|c|c|c|c|}
\hline \multirow{2}{*}{ Items } & \multicolumn{2}{|c|}{ Repeat breeding } & \multicolumn{2}{|c|}{ Dystocia } & \multicolumn{2}{|c|}{ Clinical mastitis } & \multicolumn{2}{|c|}{ Retained placenta } \\
\hline & No & Yes & No & Yes & No & Yes & No & Yes \\
\hline \multicolumn{9}{|l|}{ Stall type } \\
\hline Tie-stall & 153 & 79 & 216 & 16 & 188 & 44 & 212 & 20 \\
\hline Free-stall & 393 & 84 & 467 & 10 & 410 & 67 & 457 & 20 \\
\hline$x^{2}$ & \multicolumn{2}{|c|}{0.000} & \multicolumn{2}{|c|}{0.001} & \multicolumn{2}{|c|}{0.091} & \multicolumn{2}{|c|}{0.017} \\
\hline \multicolumn{9}{|c|}{ Resting surfaces } \\
\hline Concrete & 346 & 121 & 448 & 19 & 374 & 93 & 438 & 29 \\
\hline Sand & 104 & 26 & 126 & 4 & 120 & 10 & 121 & 9 \\
\hline Rubber & 96 & 16 & 109 & 3 & 104 & 8 & 110 & 2 \\
\hline$x^{2}$ & \multicolumn{2}{|c|}{0.021} & \multicolumn{2}{|c|}{0.722} & \multicolumn{2}{|c|}{0.000} & \multicolumn{2}{|c|}{0.149} \\
\hline
\end{tabular}

cow diseases and may impose increasing costs on milk producers and finally lead to obligatory culling (De Graves and Fetrow, 1993). In this study, it was also found that RB and $\mathrm{CM}$ were associated with resting surfaces $(\mathrm{p}<0.05$, $\mathrm{p}<0.01$ respectively). The risk of $\mathrm{CM}$ was found less for rubber bedding. This supports the findings of Valde et al. (1997), who found less CM in cows in FS housing with rubber mats compared with cows in concrete-floored stalls. In addition, other factors affecting CM might include managerial, environmental, metabolic, and nutritional problems in addition to common reproductive disorders, which collectively interact and exert adverse influences on reproduction. The $\mathrm{RB}$ also can be a major factor involved in infertility and the risk of RB was found less for rubber resting surface in this study.

The environment in which we keep our dairy cows has a dramatic effect on their health and welfare. Throughout the world, dairy cattle are managed under a wide variety of different housing systems and none of the systems are clearly superior although the FS systems have some advantages because of freedom of movement. However poorly designed stalls lead to reduced stall occupancy and the type of lying surface in the stall may affect some health and production problems (Calamari et al., 2009). There is not yet enough study regarding influence of resting surfaces and stall types on production diseases but as well-known increasing the softness of resting surface and proper stall type can increase the time that the cows spend lying down, which is an advantage for cow comfort, health and probably overall production. Deciding the kind of resting surface that is optimal for mastitis prevention and type of stall design which optimizes cow comfort and reduces the incidence of $\mathrm{RB}$ are the important questions about decreasing dairy herd turnover rates and improving cow health, production and longevity.

According to results of this study, resting surfaces and stall types directly affect milk yield and animal health, so choosing stall type and resting surface can be very important not only for milk yield and reproductive performance but also for milk quality, production efficiency and cow comfort. But in developing countries like Turkey, animal husbandry frequently appears to be of secondary importance in most of small sized herds and choices of breeders on this subject are influenced by their economic conditions. Therefore, in these countries where herds are often small sized, knowledge and technology transfer to the breeders is essential.

\section{REFERENCES}

Calamari, L., F. Calegari, and L. Stefanini. 2009. Effect of different free stall surfaces on behavioural, productive and metabolic parameters in dairy cows. Appl. Anim. Behav. Sci. 120: 9-17.

Carroll, E. J. 1977. Environmental factors in bovine mastitis. J. Am. Vet. Med. Assoc. 170:1143-1149.

Coleman, D. A., W. V. Thayne, and R. A. Oailey. 1985. Factors affecting reproductive performance of dairy cows. J. Dairy Sci. 68:1793-1803.

Cook, N. B. 2002. The influence of barn design on dairy cow hygiene, lameness, and udder health. In: Proceedings of the 35th Annual Conversation of Bovine practitioners. Madison, WI, USA. pp. 97-103.

De Graves, F. J. and J. Fetrow. 1993. Economics of mastitis and mastitis control. Vet. Clin. North Am. Food Anim. Pract. 9: 421-434.

Herlin, A. H. 1997. Comparison of lying area surfaces for dairy cows by preference, hygiene and lying down behavior. Swedish J. Agric. Res. 27:189-196.

Kara, N., A. Galic, and M. Koyuncu. 2011. Effects of stall type and bedding materials on lameness and hygiene score and effect of lameness on some reproductive problems in dairy cattle. J. Appl. Anim. Res. 39:334-338.

Kumlu, S. 2008. Beef and Dairy Cattle Breeding. 4th edn. Publications of Central Association of Turkish Cattle Breeders. Ankara, Turkey.

Le Blanc, S. J. 2008. Postpartum uterine disease and dairy herd reproductive performance: A review. Vet. J. 176:102-114.

Manninen, E, A. M. De Passilé, J. Rushen, M. Norring, and H. Saloniemi. 2002. Preferences of dairy cows kept in unheated buildings for different kind of cubicle flooring. Appl. Anim. Behav. Sci. 75:281-292.

Metcalf, J. A., S. J. Roberts, and J. D. Sutton. 1992. Variations in 
blood flow to and from the bovine mammary gland measured using transit time ultrasound and dye dilution. Res. Vet. Sci. 53:59-63.

Muller, L. D. and M. J. Owens. 1974. Factors associated with the incidence of retained placenta. J. Dairy Sci. 57:725-728.

Munksgaard, L. and P. Løvendahl. 1993. Effects of social and physical stressors on growth hormone levels in dairy cows. Can. J. Anim. Sci. 73:847-853.

Nogalski, Z. 2006. Effect of milk productivity on fertility in tied and loose-housed cows. Acta Sci. Pol. Zootech. 5:97-106.

Norring, M., E. Manninen, A. M. De Passillé, J. Rushen, L. Munksgaard, and H. Saloniemi. 2008. Effects of sand and straw bedding on the lying behavior, cleanliness, and hoof and hock injuries of dairy cows. J. Dairy Sci. 91:570-576.

Østerås, O. and A. Lund. 1988. Epidemiological analyses of the associations between bovine udder health and housing. Prev. Vet. Med. 6:79-90.

Phillips, C. J. C. and I. D. Morris. 2001. The locomotion of dairy cows on floor surfaces with different frictional properties. J. Dairy Sci. 84:623-628.

Regula, G., J. Danuser, B. Spycher, and B. Wechsler. 2004. Health and welfare of dairy cows in different husbandry systems in Switzerland. Prev. Vet. Med. 66:247-264.
Sawa, A. and M. Bogucki. 2011. Effect of housing system and milk yield on cow fertility. Arch. Tierzucht. 54:249-256.

Skrzypek, R. 2002. Somatic cell count in bulk tank milk in relation to management and technological factors. Med. Weter. 58:632635.

Stevenson, J. S. 2001. Reproductive management of dairy cows in high milk-producing herds. J. Dairy Sci. 84:128-143.

Tucker, C. B. and D. M. Weary. 2001. Cow comfort and stall design. Adv. Dairy Sci. Tech. 13:155-168.

Tucker, C. B., D. M. Weary, and D. Fraser. 2003. Effects of three types of free-stall surfaces on preferences and stall usage by dairy cows. J. Dairy Sci. 86:521-529.

Valde, J. P., D. W. Hird, M. C. Thurmond, and O. Østeras. 1997. Comparison of ketosis, clinical mastitis, somatic cell count, and reproductive performance between free stall and tie stall barns in Norwegian dairy herds with automatic feeding. Acta Vet. Scand. 38:181-192.

Zdziarski, K., H. Grodzki, T. Nałęcz-Tarwacka, P. Brzozowski, and T. Przysucha. 2002. The influence of housing system and genotype of cows on the length of use and their life time milk performance. Zeszyty Naukowe 62:29-35. 